\title{
Effects of the Southwestern Corn Borer on Aspergillus flavus Kernel Infection and Aflatoxin Accumulation in Maize Hybrids
}

\author{
G. L. Windham, W. P. Williams, and F. M. Davis, USDA-ARS, Corn Host Plant Resistance Research Unit, \\ Mississippi State, MS 39762
}

\begin{abstract}
Windham, G. L., Williams, W. P., and Davis, F. M. 1999. Effects of the southwestern corn borer on Aspergillus flavus kernel infection and aflatoxin accumulation in maize hybrids. Plant Dis. 83:535-540.

Field studies were conducted in 1995 to 1997 to determine the effect of the southwestern corn borer (SWCB) on Aspergillus flavus kernel infection and aflatoxin accumulation in maize hybrids. In 1995, when A. flavus conidia were applied to silks in a spray and SWCB neonate larvae in maize cob grits were placed in the leaf axil at the top ear of commercial hybrids, aflatoxin contamination and A. flavus kernel infection were highest in plants treated with both the fungus and the insect. In 1996, using the same inoculation and infestation techniques, aflatoxin levels and kernel infection were much lower than in 1995 and SWCB had no effect on aflatoxin contamination or kernel infection. In another study in 1996, the effect of SWCB on aflatoxin contamination and A. flavus kernel infection in hybrids resistant and susceptible to A. flavus was determined. The inoculation-infestation technique involved applying maize cob grits containing A. flavus conidia and SWCB larvae to silks. When SWCB was combined with A. flavus, aflatoxin levels and kernel infection were dramatically higher than in hybrids inoculated with A. flavus alone, regardless of whether the hybrids were resistant or susceptible to A. flavus. In 1997, the interaction of A. flavus and SWCB was determined on hybrids resistant and susceptible to A. flavus and on a commercial hybrid with and without the Bacillus thuringiensis $(B t)$ toxin. Maize cob grits were used to inoculate A. flavus and infest SWCB on the silks 7 or 21 days after midsilk (50\% of the plants in a row had silks emerged). All four hybrids had the highest levels of Aspergillus spp. kernel infection and aflatoxin contamination when A. flavus and SWCB were applied at 21 days after midsilk. These studies indicate that SWCB can substantially increase aflatoxin levels when combined with A. flavus. However, inoculation and infestation techniques, placement of the fungus and the insect, and timing of inoculation and infestation are all critical in demonstrating a synergistic relationship between A. flavus and SWCB on aflatoxin contamination of maize.
\end{abstract}

Additional keywords: Bt-toxin, corn, Diatraea grandiosella, mycotoxin, resistance, Zea mays

Aspergillus flavus preharvest infection of maize (Zea mays L.) kernels and subsequent accumulation of aflatoxin is a chronic economic and food safety problem in the southeastern United States and can be a problem in the corn belt $(10,13,14$, 16,24,34). Aflatoxin $B_{1}$ is one of the most potent carcinogens produced in nature and is commonly found in maize kernels infected with A. flavus. This aflatoxin has been the subject of numerous toxicological

Corresponding author: G. L. Windham

E-mail: gwindham@ra.msstate.edu

Contribution of the Crop Science Research Laboratory, USDA ARS, in cooperation with the Mississippi Agricultural and Forestry Experiment Station. Published with the approval of both agencies as Paper No. J9337 of the Mississippi Agricultural and Forestry Experiment Station.

Accepted for publication 3 March 1999.

Publication no. D-1999-0405-01R

This article is in the public domain and not copyrightable. It may be freely reprinted with customary crediting of the source. The American Phytopathological Society, 1999. studies $(9,12,27)$. The United States Food and Drug Administration has a tolerance threshold of $20 \mathrm{ng} / \mathrm{g}$ for aflatoxin $\mathrm{B}_{1}$ in maize (9). Grain that exceeds this level cannot be shipped through interstate commerce. Many countries have a tolerance of $10 \mathrm{ng} / \mathrm{g}$ in food supplies, while several countries have a zero tolerance for aflatoxin contamination (9).

A number of factors have been associated with aflatoxin contamination in maize. Drought stress with accompanying high temperatures has been one of the most frequent factors reported to increase the likelihood of an aflatoxin "outbreak" in maize $(8,21)$. Insect damage to developing maize ears can significantly increase aflatoxin levels in preharvest ears $(17,19,29,35)$. Damage by the corn earworm (Helicoverpa zea), fall armyworm (Spodoptera frugiperda), European corn borer (Ostrinia nubilalis), and maize weevils (Sitophilus zeamais) can result in higher levels of aflatoxin contamination (2,11,17-19). These insects increase $A$. flavus infection and aflatoxin contamination by feeding on and damaging developing kernels and by transporting A. flavus conidia into the ear (17). The relationship between insect damage and aflatoxin levels has at times been difficult to document. This relationship has been shown to vary among genotypes and locations $(2,30)$.

The southwestern corn borer (Diatraea grandiosella) is an important pest of maize in the United States $(4,6,22,32)$; however, little information is available on how this pest interacts with A. flavus on maize. The southwestern corn borer (SWCB) entered the United States in the early 1900s from Mexico and is now distributed from the Southwest to the Southeast regions of the United States, up into the Midwest. Firstgeneration larvae attack whorl-stage maize, feeding on meristematic tissue before tunneling into the stalk (4). Second-generation larvae (those attacking maize in the reproductive stage) also feed on the stalk but also will feed on the shank, husks, cobs, and kernels of developing ears (7). Yield losses caused by first- and second-generation SWCB larvae range from 3 to $9 \%$ $(7,32)$. Losses are due to stunting, stalk breakage and lodging, and reduced grain production.

Because SWCB can cause significant ear damage and population levels of this insect are increasing in the Southeast, studies were conducted to determine the effect of SWCB on A. flavus kernel infection and aflatoxin accumulation in developing maize ears in the field. Inoculation and infestation techniques were evaluated to determine which methods lead to establishment of both pests in developing maize ears.

\section{MATERIALS AND METHODS}

General. Studies were conducted at the Plant Science Farm, Mississippi State, Mississippi, in 1995, 1996, and 1997. Single-row, $5.1-\mathrm{m}$ plots spaced $0.96 \mathrm{~m}$ apart were thinned to 20 plants/plot. Plots received supplemental irrigation during ear development each growing season to limit drought stress. Ambient air temperatures ranged from 22 to $27^{\circ} \mathrm{C}$ during silking and ear development in 1995, 1996, and 1997.

Inoculum and insect production. $A$. flavus isolate NRRL 3357, which is known to produce aflatoxin in maize grain (23), was used as inoculum in all experiments. Inoculum was increased on sterile maize cob grits (40 mesh, Grit-O'-Cobs, Maumee, $\mathrm{OH}$ ) in 500-ml flasks, each containing $50 \mathrm{~g}$ of grits and $100 \mathrm{ml}$ of $\mathrm{H}_{2} \mathrm{O}$, and incubated at $28^{\circ} \mathrm{C}$. Conidia were 
washed from the grits using sterile distilled water containing 20 drops of Tween 20/liter and filtered through four layers of sterile cheesecloth. The concentration of conidia was determined with a hemacytometer and adjusted with sterile distilled water to $9 \times 10^{7}$ conidia $/ \mathrm{ml}$. Inoculum not immediately used was refrigerated at $4^{\circ} \mathrm{C}$.

SWCB neonate larvae used in our experiments were obtained from our research unit's insect-rearing laboratory. The procedures used to rear this insect have been described (3).

Experiment 1. In 1995, three commercial hybrids (Terra Brand TR1185, Pioneer Brand 3163, and Hyperformance Brand HB847002) were planted on 17 April. The experimental design was a randomized complete block (RCB) with treatments factorially arranged and replicated five times. Treatments included A. flavus, SWCB, A. flavus plus SWCB, and a noninoculated, non-infested control. Hybrids were inoculated with $A$. flavus and infested with SWCB beginning on 5 July, after silks had emerged. Silks of the top ear of each plant were inoculated with a 3.4-ml suspension containing $3 \times 10^{8} \mathrm{~A}$. flavus conidia using a tree-marking gun fitted with a spray nozzle (36). Plants were infested with SWCB using a hand-operated dispenser (5). The dispenser was used to place 30 neonate larvae mixed in maize cob grits in the leaf axil at the top ear. Inoculations and infestations continued weekly for another 3 weeks. Side-needle inoculations (36) were made 7 days after midsilk to confirm viability of the A. flavus inoculum.

In 1996, the experiment was repeated with the same three hybrids plus Pioneer 3156 and was planted on 29 April. Treatments and inoculation and infestation techniques were the same as those used in 1995. A. flavus inoculations and SWCB infestations began on 3 July and continued weekly until 24 July.

Experiment 2. In 1996, 10 hybrids made by crossing parental lines with varying levels of resistance to A. flavus were used to study the effect of SWCB on aflatoxin accumulation and $A$. flavus kernel infection. The hybrids were planted 29 April in a RCB design with four replications. Treatments included A. flavus, A. flavus plus SWCB, and a non-inoculated, non-infested control. Fungal inoculum was prepared as reported above by increasing A. flavus on moist maize cob grits. Cultures were removed from flasks and spread on aluminum foil and allowed to air dry for $24 \mathrm{~h}$. Cultures were passed through an 8mesh (2.362-mm opening) sieve and then mixed with sterile maize cob grits on a 1:1 (vol/vol) ratio and placed in 1-liter plastic bottles. The fungal inoculations and insect infestations were made 21 days after midsilk $(50 \%$ of the plants in the row had silks emerged). Wax-paper shoot bags (Lawson \#214, Northfield, IL) open at both ends were placed over the top ear of each plant.
The maize cob grits infested with spores of A. flavus was placed on silks inside the shoot bags using the same hand-operated dispenser used to infest SWCB in experiment 1 . SWCB infestations were made 24 $\mathrm{h}$ after fungal inoculations using the handoperator dispenser to place 15 neonate larvae on silks inside the shoot bags and 15 neonate larvae were placed in the leaf axil of the ear.

Experiment 3. In 1997, a field study was conducted to determine the interactions of A. flavus and SWCB on an A. flavus-resistant hybrid $(\mathrm{Mp} 420 \times \mathrm{Tx} 601)$, an A. flavus-susceptible hybrid (Ab24E $\times$ SC229), a transgenic Bacillus thuringiensis (Bt) hybrid (N6800Bt), and a nontransgenic version (N6800). Seed of the transgenic (N6800Bt) and nontransgenic (N6800) hybrids were provided by Novartis Seeds. The gene used to confer insect resistance in the transgenic hybrid was $\operatorname{cryIA}(b)$ and is expressed in all ear tissues (31). The four hybrids were planted on 17 April in a split plot design with hybrids in main plots; treatments were replicated five times. Treatments included A. flavus, SWCB, A. flavus plus SWCB, and a noninoculated, non-infested control. Fungal inoculations and insect infestations were made 7 or 21 days after midsilk. Inoculation and infestation techniques were the same used in experiment 2 .

Harvests, insect ratings, aflatoxin analyses, and kernel infection. Mature ears in all experiments were hand harvested approximately 63 days after midsilk and dried at $38^{\circ} \mathrm{C}$ for 7 days. Ears for experiments 1 and 3 were rated for feeding damage by SWCB and other lepidopterous pests. Ears from each plot were scored collectively using the following scale: $1=$ ear-tip damage only; 2 = ear-tip damage plus slight damage below the tip on a few ears; 3 = ear-tip damage plus little to moderate damage below the tip on about one quarter of the ears; 4 = ear-tip damage plus moderate to heavy damage below the tip on about half of the ears; 5 = ear-tip damage plus moderate to heavy damage below the tip on three quarters of the ears; and 6 = ear-tip damage plus moderate to heavy damage below the tip on all of the ears.

Ears were machine shelled and grain samples from each row were poured into a sample splitter twice to mix the grain. Half of the grain was used for aflatoxin analyses and the other half was used for determination of kernel infection. Grain samples used in aflatoxin analyses were ground using a Romer mill (Union, MO). Aflatoxin contamination in $50 \mathrm{~g}$ of subsamples from each plot was determined using the Vicam Aflatest (Watertown, MA). This procedure can detect aflatoxins $\left(B_{1}, B_{2}, G_{1}\right.$, $\mathrm{G}_{2}$ ) at concentrations as low as $2 \mathrm{ng} / \mathrm{g}$.

Kernels evaluated for $A$. flavus infection were surface sterilized by dipping momentarily (5 s) in 70\% ethanol, soaking for $3 \mathrm{~min}$ in $1.5 \% \mathrm{NaOCl}$, and rinsing in ster- ile distilled water. The kernels were placed in 100-mm petri dishes (13 kernels per dish, 390 kernels per plot) on Czapek solution agar amended with $7.5 \% \mathrm{NaCl}$ to restrict growth of other fungi and bacteria. After 7 days at $28^{\circ} \mathrm{C}$, kernels were examined for A. flavus growth.

Data analyses. Aflatoxin data were transformed to stabilize variance of the data. Data were subjected to analysis of variance with the SAS general linear models procedure (SAS Institute, Cary, NC). Data were analyzed to determine interactions among genotypes, fungal and insect treatments, and inoculation or infestation dates. Means were compared by the least significant difference test (LSD) at $P=$ 0.05 .

\section{RESULTS}

Experiment 1. Because of significant interactions among hybrids and treatments, the data are reported for each hybrid. In 1995, plants receiving both $A$. flavus and SWCB treatments had significantly higher levels of aflatoxin accumulation when compared to plants inoculated with only $A$. flavus (Table 1). Aflatoxin levels ranged from 1,387 to $1,928 \mathrm{ng} / \mathrm{g}$ for hybrids Pioneer 3163 and HB847002, respectively. 'Pioneer 3163' and 'HB847002' plants receiving both A. flavus and SWCB treatments had significantly more aflatoxin than plants infested with only SWCB. Plants for hybrids TR1185 and HB847002 infested with SWCB treatments had significantly higher amounts of aflatoxin than plants inoculated with A. flavus alone. Non-inoculated, non-infested plots had relatively high aflatoxin contamination, with amounts ranging from 43 to 178 for hybrids TR1185 and Pioneer 3163, respectively.

In 1996, aflatoxin contamination for all hybrids across all treatments was much lower than the levels observed in 1995 (Table 1). The only statistically significant differences for aflatoxin contamination were between the $A$. flavus treatment and the control for hybrid TR1185 and between plants receiving both A. flavus and SWCB and plants infested with SWCB for hybrid HB847002. 'Pioneer 3156' plants inoculated with $A$. flavus and infested with SWCB had aflatoxin levels numerically higher than all other treatments, but there were no statistically significant differences among treatments.

A. flavus kernel infection in 1995 followed a pattern similar to aflatoxin contamination (Table 1). Kernel infection for all three commercial hybrids was significantly higher for plants inoculated with $A$. flavus and infested with SWCB compared to plants inoculated with A. flavus alone. Plants of all three hybrids treated with both the fungus and insect had significantly higher levels of kernel infection than plants inoculated with fungus alone. Kernel infection in plants infested with SWCB only 
in all hybrids was numerically higher than kernel infection of plants inoculated with A. flavus alone.

Kernel infection in the same commercial hybrids was much less in 1996 than in 1995 (Table 1). The only significant difference among treatments was for hybrid TR1185. The A. flavus plus SWCB treatment and $A$. flavus alone had higher levels of kernel infection compared to plants treated with SWCB alone. Although 'Pioneer 3156' and 'HB847002' plants treated with both the fungus and insect, and with SWCB alone, had higher levels of kernel infection compared to the fungus alone or control plots, there was no significant difference between these treatments. 'Pioneer 3163' had just the opposite trend, with highest kernel infection in plants with the fungus alone and the lowest levels in plants infested with just the insect or the fungus plus the insect. Natural infection of kernels by $A$. flavus in plants of the noninoculated, non-infested control was lower than control plants in 1995.

Insect feeding damage was significantly higher in all plots artificially infested with SWCB compared to noninfested plots for all hybrids in 1995 and 1996 (Table 1). A limited amount of insect damage was observed in plots not infested with SWCB in 1995. However, natural insect pressure was considerably higher in 1996. Insect rating ranged from 2.6 to 3.8 in control plots and from 3.0 to 3.6 in plots with A. flavus alone. Most of the insect damage on nonSWCB infested plants was due to corn earworm.

Experiment 2. Aflatoxin contamination was dramatically higher for all hybrids when SWCB was included with A. flavus regardless of whether hybrids were made from A. flavus-resistant or -susceptible parents (Table 2). Hybrid Ab24E × SC229 (A. flavus susceptible) had the highest level of aflatoxin contamination $(5,080 \mathrm{ng} / \mathrm{g})$ of any hybrid when A. flavus and SWCB were placed together on the silks and had much lower aflatoxin contamination (185 $\mathrm{ng} / \mathrm{g}$ ) when inoculated with $A$. flavus alone. Aflatoxin contamination was much higher in A. flavus-resistant hybrids when treated with both the fungus and insect compared to the same hybrids treated only with the fungus. Plots of hybrids Mp313E $\times$ SC212 and Mp313E $\times$ Mp420 had 5 and $6 \mathrm{ng} / \mathrm{g}$ of aflatoxin for the A. flavus alone, respectively; however, when SWCB was included with $A$. flavus, aflatoxin levels increased to 770 and $298 \mathrm{ng} / \mathrm{g}$, respectively. Hybrids Gt-mas:gk $\times$ Mp313E and Tex6 $\times$ Mo18w were the only hybrids that did not have significantly higher levels of aflatoxin contamination in plots treated with both the fungus and insect compared to the fungus alone treatment. A. flavus-susceptible hybrids $($ Ab24E $\times$ SC229, GA209 $\times$ Mp68:616, and GA209 $\times$ SC212m) inoculated with $A$. flavus and infested with SWCB had much higher levels of aflatoxin contamination compared to several of the A. flavus-resistant hybrids (Gt-mas:gk $\times$ $\mathrm{Mp} 313 \mathrm{E}$ and $\mathrm{Mp} 313 \mathrm{E} \times \mathrm{Mp} 420)$. The control plots of all of the hybrids had very little aflatoxin contamination compared to the other treatments.

Seven hybrids had significantly higher levels of A. flavus kernel infection when SWCB was included with the fungus compared to the fungus alone (Table 2). Hybrid GA209 × Mp68:616 treated with A. flavus and SWCB had the highest amount of kernel infection $(4.8 \%)$ for any hybrid-treatment combination in this experiment. Hy- brid Mp313E $\times$ Mp420 had the lowest level of kernel infection of all hybrids treated with both SWCB and A. flavus. Kernel infection for three of the resistant hybrids (Gt-mas:gk $\times$ Mp313E, Mp313E $\times$ Mp420, and Mp420 $\times$ Tx601) was not significantly higher in plots treated with both SWCB and A. flavus compared to plots treated with $A$. flavus alone. Kernel infection was low in all plots treated with A. flavus alone and also in the control plots.

Experiment 3. There was a significant $(P=0.008)$ interaction among fungal and insect treatments and inoculation or infestation dates for aflatoxin contamination. Data are reported for each treatment for the two dates. The A. flavus and SWCB treatment at 21 days after midsilk had the highest levels of aflatoxin contamination for all four hybrids (Table 3). For that treatment, hybrid Ab24E $\times$ SC229 had the highest aflatoxin level (706 ng/g) and hybrid N6800Bt had the lowest aflatoxin level (290 ng/g). When A. flavus or SWCB was applied alone at either 7 or 21 days after midsilk, aflatoxin contamination in hybrids Mp420 × Tx601 and N6800 was significantly lower compared to the A. flavus plus SWCB treatment at 21 days after midsilk. The A. flavus plus SWCB treatment applied at 7 days after midsilk was significantly higher than either A. flavus or SWCB applied alone 7 or 21 days after midsilk only on the A. flavus-resistant hybrid (Mp420 × Tx601).

Aspergillus spp. kernel infection was highest in three hybrids treated with $A$. flavus and SWCB 21 days after midsilk (Table 3). Kernel infection for this treatment ranged from $1.5 \%$ for $\mathrm{cv}$. N6800Bt to $4.1 \%$ for hybrid N6800. Kernel infection

Table 1. Aflatoxin accumulation, Aspergillus flavus kernel infection, and insect damage in maize hybrids inoculated with A. flavus (Af), infested with the southwestern corn borer (SWCB), or both organisms

\begin{tabular}{|c|c|c|c|c|c|c|}
\hline \multirow[b]{2}{*}{ Hybrid and treatment } & \multicolumn{2}{|c|}{ Aflatoxin (ng/g) } & \multicolumn{2}{|c|}{ Kernel infection $(\%)$} & \multicolumn{2}{|c|}{ Insect damage rating $^{x}$} \\
\hline & 1995 & 1996 & 1995 & 1996 & 1995 & 1996 \\
\hline \multicolumn{7}{|l|}{ Teffa TR1185 } \\
\hline Af + SWCB & $1,480 a^{y}$ & $60 \mathrm{ab}$ & $5.8 \mathrm{a}$ & $1.7 \mathrm{ab}$ & $4.8 \mathrm{a}$ & $5.2 \mathrm{a}$ \\
\hline SWCB & $1,182 \mathrm{a}$ & $57 \mathrm{ab}$ & $4.4 \mathrm{ab}$ & $0.4 \mathrm{c}$ & $4.5 \mathrm{a}$ & $5.4 \mathrm{a}$ \\
\hline Af & $113 \mathrm{~b}$ & $86 \mathrm{a}$ & $3.3 \mathrm{~b}$ & $2.4 \mathrm{a}$ & $1.8 \mathrm{~b}$ & $3.4 \mathrm{~b}$ \\
\hline Control & $43 \mathrm{~b}$ & $25 \mathrm{~b}$ & $1.1 \mathrm{c}$ & $0.9 \mathrm{bc}$ & $1.7 \mathrm{~b}$ & $3.2 \mathrm{~b}$ \\
\hline \multicolumn{7}{|l|}{ Pioneer 3163} \\
\hline $\mathrm{Af}+\mathrm{SWCB}$ & $1,387 \mathrm{a}$ & $8 \mathrm{a}$ & $8.5 \mathrm{a}$ & $0.7 \mathrm{a}$ & $5.0 \mathrm{a}$ & $5.4 \mathrm{a}$ \\
\hline SWCB & $532 \mathrm{ab}$ & $38 \mathrm{a}$ & $5.6 \mathrm{ab}$ & $0.6 \mathrm{a}$ & $4.7 \mathrm{a}$ & $5.2 \mathrm{a}$ \\
\hline Af & $171 \mathrm{~b}$ & $79 \mathrm{a}$ & $3.1 \mathrm{~b}$ & $3.3 \mathrm{a}$ & $1.5 \mathrm{~b}$ & $3.4 \mathrm{~b}$ \\
\hline Control & $178 \mathrm{~b}$ & $24 \mathrm{a}$ & $3.0 \mathrm{~b}$ & $2.5 \mathrm{a}$ & $1.8 \mathrm{~b}$ & $3.2 \mathrm{~b}$ \\
\hline \multicolumn{7}{|l|}{ Pioneer 3156} \\
\hline $\mathrm{Af}+\mathrm{SWCB}$ & $\ldots^{\mathrm{z}}$ & $168 \mathrm{a}$ & $\ldots$ & $1.6 \mathrm{a}$ & $\ldots$ & $5.0 \mathrm{a}$ \\
\hline SWCB & $\ldots$ & $8 \mathrm{ab}$ & $\ldots$ & $1.9 \mathrm{a}$ & $\ldots$ & $5.4 \mathrm{a}$ \\
\hline Af & $\ldots$ & $29 a$ & $\ldots$ & $0.4 \mathrm{a}$ & $\ldots$ & $3.0 \mathrm{~b}$ \\
\hline Control & $\ldots$ & $3 \mathrm{~b}$ & $\ldots$ & $0.5 \mathrm{a}$ & $\ldots$ & $2.6 \mathrm{~b}$ \\
\hline \multicolumn{7}{|l|}{ HB847002 } \\
\hline $\mathrm{Af}+\mathrm{SWCB}$ & $1,928 \mathrm{a}$ & $105 \mathrm{a}$ & $9.2 \mathrm{a}$ & $2.5 \mathrm{a}$ & $4.8 \mathrm{a}$ & $5.4 \mathrm{a}$ \\
\hline SWCB & $660 \mathrm{~b}$ & $18 \mathrm{~b}$ & $6.1 \mathrm{ab}$ & $2.1 \mathrm{a}$ & $4.6 \mathrm{a}$ & $5.8 \mathrm{a}$ \\
\hline Af & $111 \mathrm{c}$ & $88 \mathrm{a}$ & $2.6 \mathrm{~b}$ & $1.0 \mathrm{a}$ & $1.6 \mathrm{~b}$ & $3.6 \mathrm{~b}$ \\
\hline Control & $56 \mathrm{c}$ & $33 a b$ & $2.2 \mathrm{~b}$ & $0.5 \mathrm{a}$ & $1.8 \mathrm{~b}$ & $3.8 \mathrm{~b}$ \\
\hline
\end{tabular}

${ }^{\mathrm{x}}$ Ratings based on a 1 to 6 scale, where $1=$ ear tip damage only and $6=$ ear tip damage plus moderate to heavy damage below tip on all of the ears from a plot.

y Values within a column by hybrid followed by the same letter are not significantly different, least significant difference $P=0.05$.

${ }^{\mathrm{z}}$ Data are not available. 
of plants treated with A. flavus or SWCB alone at either 7 or 21 days after midsilk was $1.0 \%$ or less, with only two exceptions. Natural A. flavus infection of the hybrids ranged from 0.4 to $1.1 \%$ for hybrids Ab24E $\times$ SC229 and N6800Bt, respectively. The only differences across hybrids was for the SWCB treatment at 7 days after midsilk and in the control treatment.

Insect damage ratings were generally higher for all SWCB treatments made 7 days after midsilk compared to insects applications made 21 days after midsilk (Table 3). Hybrid N6800Bt had the lowest insect damage ratings compared to the other three hybrids for all SWCB treatments. A limited amount of damage was caused by a natural infestation of corn earworm on non-SWCB-infested plants.

\section{DISCUSSION}

Our studies demonstrated that SWCB can dramatically increase aflatoxin con- tamination on maize. Inoculation or infestation method, placement of the fungus and insect, and timing of inoculation and infestation are all critical in demonstrating a synergistic relationship between A. flavus and SWCB on maize. A. flavus-resistant hybrids were not effective in limiting aflatoxin contamination in the presence of A. flavus and SWCB. Multiple pest-resistant hybrids are needed to suppress insect feeding damage on maize ears and limit $A$. flavus infection and subsequent aflatoxin production.

Our studies also demonstrated some of the problems in documenting the relationship between insect damage and aflatoxin contamination. In 1995, for experiment 1 , the highest levels of aflatoxin contamination for all hybrids was the A. flavus plus SWCB treatment. However, in 1996, no consistent association between SWCB and aflatoxin contamination was observed. The inoculation technique for A. flavus for both years of that experiment consisted of spraying conidia on the silks. The SWCB

Table 2. Effects of the southwestern corn borer (SWCB) and Aspergillus flavus (Af) on aflatoxin contamination and kernel infection in maize hybrids with aflatoxin resistant (R), intermediate (I), or susceptible (S) parents

\begin{tabular}{|c|c|c|}
\hline Hybrid and treatment & Aflatoxin (ng/g) & Aspergillus kernel infection (\%) \\
\hline \multicolumn{3}{|l|}{$\mathrm{Ab} 24 \mathrm{E} \times \mathrm{SC} 229(\mathrm{~S} \times \mathrm{S})$} \\
\hline $\mathrm{Af}+\mathrm{SWCB}$ & $5,080 \mathrm{a}^{\mathrm{z}}$ & $4.2 \mathrm{a}$ \\
\hline Af & $185 \mathrm{~b}$ & $0.7 \mathrm{~b}$ \\
\hline Control & $4 \mathrm{c}$ & $0.3 \mathrm{~b}$ \\
\hline \multicolumn{3}{|c|}{ GA209 $\times$ Mp68:616 $(\mathrm{S} \times \mathrm{S})$} \\
\hline $\mathrm{Af}+\mathrm{SWCB}$ & $2,545 \mathrm{a}$ & $4.8 \mathrm{a}$ \\
\hline Af & $473 \mathrm{~b}$ & $0.6 \mathrm{~b}$ \\
\hline Control & $15 \mathrm{c}$ & $0.7 \mathrm{~b}$ \\
\hline \multicolumn{3}{|l|}{$\mathrm{GA} 209 \times \mathrm{SC} 212 \mathrm{~m}(\mathrm{~S} \times \mathrm{S})$} \\
\hline $\mathrm{Af}+\mathrm{SWCB}$ & 3,930 a & $3.9 \mathrm{a}$ \\
\hline Af & $134 \mathrm{~b}$ & $1.1 \mathrm{~b}$ \\
\hline Control & $42 \mathrm{~b}$ & $0.3 \mathrm{~b}$ \\
\hline \multicolumn{3}{|c|}{ Gt-mas:gk $\times \operatorname{Mp} 313 \mathrm{E}(\mathrm{R} \times \mathrm{R})$} \\
\hline $\mathrm{Af}+\mathrm{SWCB}$ & $265 \mathrm{a}$ & $1.2 \mathrm{a}$ \\
\hline Af & $87 \mathrm{ab}$ & $0.2 \mathrm{a}$ \\
\hline Control & $24 \mathrm{~b}$ & $0.1 \mathrm{a}$ \\
\hline \multicolumn{3}{|c|}{ Gt-mas:gk $\times$ Mp420 $(\mathrm{R} \times \mathrm{R})$} \\
\hline $\mathrm{Af}+\mathrm{SWCB}$ & $1,303 \mathrm{a}$ & $2.8 \mathrm{a}$ \\
\hline Af & $85 \mathrm{~b}$ & $0.2 \mathrm{~b}$ \\
\hline Control & $4 \mathrm{c}$ & $0.2 \mathrm{~b}$ \\
\hline \multicolumn{3}{|c|}{$\mathrm{Mp} 313 \mathrm{E} \times \mathrm{Mp} 420(\mathrm{R} \times \mathrm{R})$} \\
\hline $\mathrm{Af}+\mathrm{SWCB}$ & $298 \mathrm{a}$ & $1.0 \mathrm{a}$ \\
\hline Af & $6 \mathrm{~b}$ & $0.1 \mathrm{a}$ \\
\hline Control & $2 \mathrm{~b}$ & $0 \quad \mathrm{a}$ \\
\hline \multicolumn{3}{|c|}{$\mathrm{Mp} 313 \mathrm{E} \times \mathrm{SC} 212 \mathrm{~m}(\mathrm{R} \times \mathrm{S})$} \\
\hline $\mathrm{Af}+\mathrm{SWCB}$ & $770 \mathrm{a}$ & $1.2 \mathrm{a}$ \\
\hline Af & $5 \mathrm{~b}$ & $0.1 \mathrm{~b}$ \\
\hline Control & $5 \mathrm{~b}$ & $0.1 \mathrm{~b}$ \\
\hline \multicolumn{3}{|l|}{$\mathrm{Mp} 420 \times \mathrm{SC} 212 \mathrm{~m}(\mathrm{R} \times \mathrm{S})$} \\
\hline Af + SWCB & $432 \mathrm{a}$ & $1.2 \mathrm{a}$ \\
\hline Af & $14 \mathrm{~b}$ & $0.1 \mathrm{~b}$ \\
\hline Control & $2 \mathrm{~b}$ & $0.1 \mathrm{~b}$ \\
\hline \multicolumn{3}{|l|}{$\mathrm{Mp} 420 \times \mathrm{T} \times 601(\mathrm{R} \times \mathrm{R})$} \\
\hline $\mathrm{Af}+\mathrm{SWCB}$ & $717 \mathrm{a}$ & $1.9 \mathrm{a}$ \\
\hline Af & $33 \mathrm{~b}$ & $0.2 \mathrm{a}$ \\
\hline Control & $6 \mathrm{~b}$ & $0.1 \mathrm{a}$ \\
\hline \multicolumn{3}{|l|}{ Tex6 $\times$ Mo18W $(\mathrm{R} \times \mathrm{I})$} \\
\hline $\mathrm{Af}+\mathrm{SWCB}$ & $697 \mathrm{a}$ & $1.3 \mathrm{a}$ \\
\hline Af & $201 \mathrm{ab}$ & $0.3 \mathrm{~b}$ \\
\hline Control & $6 \mathrm{~b}$ & $0.3 \mathrm{~b}$ \\
\hline
\end{tabular}

z Values within a column by hybrid followed by the same letter are not significantly different, least significant difference $P=0.05$. infestation technique consisted of placing larvae at the base of the ear in the leaf axil. Although both the fungus and insect were placed physically on the same ear, apparently, in 1996, they were not close enough to establish a synergistic relationship in regards to aflatoxin contamination. Spraying A. flavus spores on silks has not been consistent in establishing the fungus inside ears at our location (G. Windham, unpublished). In fact, in 1995, the interaction between A. flavus and SWCB may have been observed due to a high level of natural infection by A. flavus. SWCB treatments with high levels of aflatoxin contamination were probably the result of this natural infection that occurred as a result of insect feeding. Viability of the A. flavus inoculum was not a problem in either 1995 or 1996. Plants side-needle inoculated at the time of inoculation and infestation of test plots yielded high levels of kernel infection and aflatoxin contamination. In 1996, aflatoxin contamination in the four commercial hybrids ranged from 628 to $1,390 \mathrm{ng} / \mathrm{g}$ when plants were side-needle inoculated.

In experiment 2 , in an effort to improve the A. flavus inoculation technique, a handoperated dispenser previously developed to infest plants with lepidopterans was used to apply a mixture of corn cob grits mixed with A. flavus spores on maize silks. By placing the fungal inoculum on the silks and following with an application of SWCB, the larvae should have been well covered with A. flavus spores before entering the ears. The transportation of $A$. flavus spores by various insect developmental stages has been well documented in increasing aflatoxin contamination in corn $(15,17,18)$. Inoculating the fungus and infesting silks with the insect with the hand-operated dispenser worked well in experiments 2 and 3 in demonstrating the synergistic interaction between A. flavus and SWCB in regards to aflatoxin contamination.

Having resistance to A. flavus alone was not sufficient in reducing aflatoxin contamination when plants were simultaneously attacked by A. flavus and SWCB. In experiments 2 and 3 , hybrids produced by crossing highly resistant parents, such as cvs. Mp313E (25,33), Mp420 (26,33), Gtmas:gk (1), and Tex6 (1), had dramatically higher levels of aflatoxin contamination when treated with both the A. flavus and SWCB. Commercial maize hybrids may need resistance to both A. flavus and insect pests to effectively suppress aflatoxin contamination. Very little information is available on multiple resistance to A. flavus and insect pests on maize. Recently, maize lines with resistance (cv. $\mathrm{Mp420}$ ) and intermediate resistance (cv. SC54) to A. flavus kernel infection were found to be less susceptible to the maize weevil (28). Further efforts need to be made to combine fungal and insect resis- 
tance in maize germplasm to protect developing ears. flavus. Other $B t$ hybrids inoculated with $A$. flavus at our location have had equally high levels (>1,700 ng/g) of aflatoxin contamination (G. Windham, unpublished). However, in some studies $B t$ hybrids can reduce maize ear rot. In a recent study (20), maize hybrids genetically engineered with $B t$ genes had lower incidence and severity of Fusarium ear rot and lower incidence of symptomless kernel infection compared to non- $B t$ hybrids. Also, transformed plants manually infested with European corn borer had greatly reduced levels of Fusarium ear rot incidence and severity. Even though insect damage ratings were generally lower for the $B t$ hybrid, apparently the amount of insect feeding was sufficient for A. flavus establishment and subsequent aflatoxin contamination. Although sustaining less insect damage (feeding), Bt hybrids may allow enough damage to predispose kernels to $A$. flavus infection.

Timing of inoculation with A. flavus and infestation with SWCB may also be im-
The $B t$ hybrid had relatively high levels of aflatoxin when inoculated only with $A$.

portant in demonstrating a relationship between insect damage and aflatoxin contamination. When A. flavus and SWCB were applied to the silks at 21 days after midsilk, aflatoxin levels were generally higher than when both were applied at 7 days after midsilk. In contrast, aflatoxin contamination of plants inoculated with $A$. flavus alone or infested with SWCB alone was similar regardless of the application date.

\section{ACKNOWLEDGMENTS}

We thank E. L. Scruggs, L. Owens, P. Buckley, G. Matthews, Jr., P. Tranum, and S. Wolf for excellent technical assistance.

\section{LITERATURE CITED}

1. Campbell, K. W., and White, D. G. 1995. Evaluation of corn genotypes for resistance to Aspergillus ear rot, kernel infection, and aflatoxin production. Plant Dis. 79:1039-1045.

2. Darrah, L. L., Lillehoj, E. B., Zuber, M. S., Scott, G. E., Thompson, D., West, D. R., Widstrom, N. W., and Fortnum, B. A. 1987. Inheritance of aflatoxin $B_{1}$ levels in maize kernels under modified natural inoculation with Aspergillus flavus. Crop Sci. 27:869-872.

3. Davis, F. M. 1989. Rearing the southwestern corn borer and fall armyworms at Mississippi State. Pages 27-36 in: Toward Insect-Resistant Maize for the Third World, Proc. Intl. Symp. Methodologies for Developing Host Plant Re-

Table 3. Aflatoxin accumulation, kernel infection, and insect damage ratings for ears infested with the southwestern corn borer (SWCB), inoculated with Aspergillus flavus (Af), or both organisms at two inoculation or infestation dates

\begin{tabular}{|c|c|c|c|c|}
\hline Hybrid and treatment & Date $^{\mathrm{x}}$ & Aflatoxin (ng/g) & Kernel infection & $\begin{array}{c}\text { Insect damage } \\
\text { ratings }^{\mathrm{y}}\end{array}$ \\
\hline \multicolumn{5}{|l|}{$\mathrm{Ab} 24 \mathrm{E} \times \mathrm{SC} 229$} \\
\hline $\mathrm{Af}+\mathrm{SWCB}$ & 21 & $706 a^{z}$ & $2.6 \mathrm{a}$ & $3.0 \mathrm{~b}$ \\
\hline $\mathrm{Af}+\mathrm{SWCB}$ & 7 & $151 \mathrm{ab}$ & $2.1 \mathrm{a}$ & $4.2 \mathrm{a}$ \\
\hline Af & 21 & $78 \mathrm{ab}$ & $0.7 \mathrm{~b}$ & $2.6 \mathrm{~b}$ \\
\hline Af & 7 & $72 a b$ & $0.5 \mathrm{~b}$ & $2.8 \mathrm{~b}$ \\
\hline SWCB & 21 & $29 \mathrm{~b}$ & $0.4 \mathrm{~b}$ & $2.8 \mathrm{~b}$ \\
\hline SWCB & 7 & $5 \mathrm{~b}$ & $0.3 \mathrm{~b}$ & $4.2 \mathrm{a}$ \\
\hline Control & $\ldots$ & $1 \mathrm{c}$ & $0.4 \mathrm{~b}$ & $2.8 \mathrm{~b}$ \\
\hline \multicolumn{5}{|l|}{ Mp420 × Тх601 } \\
\hline Af + SWCB & 21 & $545 \mathrm{a}$ & $3.5 \mathrm{a}$ & $2.0 \mathrm{c}$ \\
\hline $\mathrm{Af}+\mathrm{SWCB}$ & 7 & $133 \mathrm{a}$ & $1.4 \mathrm{~b}$ & $3.4 \mathrm{a}$ \\
\hline Af & 21 & $13 \mathrm{~b}$ & $0.8 \mathrm{~b}$ & $2.2 \mathrm{bc}$ \\
\hline Af & 7 & $16 \mathrm{~b}$ & $0.7 \mathrm{~b}$ & $2.0 \mathrm{c}$ \\
\hline SWCB & 21 & $6 \mathrm{~b}$ & $0.3 \mathrm{~b}$ & $3.2 \mathrm{ab}$ \\
\hline SWCB & 7 & $10 \mathrm{~b}$ & $0.9 \mathrm{~b}$ & $3.2 \mathrm{ab}$ \\
\hline Control & $\ldots$ & $2 \mathrm{~b}$ & $0.5 \mathrm{~b}$ & $2.4 a b c$ \\
\hline \multicolumn{5}{|l|}{ N6800 } \\
\hline $\mathrm{Af}+\mathrm{SWCB}$ & 21 & $650 \mathrm{a}$ & $4.1 \mathrm{a}$ & $2.8 \mathrm{ab}$ \\
\hline $\mathrm{Af}+\mathrm{SWCB}$ & 7 & $136 a b$ & $1.4 \mathrm{~b}$ & $3.0 \mathrm{ab}$ \\
\hline Af & 21 & $45 \mathrm{~b}$ & $0.3 \mathrm{~b}$ & $3.0 \mathrm{ab}$ \\
\hline Af & 7 & $45 \mathrm{~b}$ & $1.2 \mathrm{~b}$ & $2.2 \mathrm{~b}$ \\
\hline SWCB & 21 & $41 \mathrm{bc}$ & $1.0 \mathrm{~b}$ & $3.8 \mathrm{a}$ \\
\hline SWCB & 7 & $19 \mathrm{c}$ & $0.6 \mathrm{~b}$ & $3.2 \mathrm{ab}$ \\
\hline Control & $\ldots$ & $6 \mathrm{c}$ & $0.5 \mathrm{~b}$ & $2.2 \mathrm{~b}$ \\
\hline \multicolumn{5}{|l|}{ N6800 Bt } \\
\hline $\mathrm{Af}+\mathrm{SWCB}$ & 21 & 290 a & $1.5 \mathrm{a}$ & $1.8 \mathrm{a}$ \\
\hline $\mathrm{Af}+\mathrm{SWCB}$ & 7 & $83 \mathrm{a}$ & $1.4 \mathrm{a}$ & $1.6 \mathrm{a}$ \\
\hline Af & 21 & $145 \mathrm{a}$ & $1.0 \mathrm{a}$ & $2.0 \mathrm{a}$ \\
\hline Af & 7 & $166 \mathrm{a}$ & $0.7 \mathrm{a}$ & $2.0 \mathrm{a}$ \\
\hline SWCB & 21 & $5 \mathrm{~b}$ & $2.5 \mathrm{a}$ & $2.0 \mathrm{a}$ \\
\hline SWCB & 7 & $4 \mathrm{~b}$ & $0.2 \mathrm{a}$ & $2.2 \mathrm{a}$ \\
\hline Control & $\ldots$ & $17 \mathrm{~b}$ & $1.1 \mathrm{a}$ & $2.0 \mathrm{a}$ \\
\hline
\end{tabular}

${ }^{\mathrm{x}}$ Inoculation or infestation date, days after midsilk.

${ }^{y}$ Ratings based on a 1 to 6 scale, where 1 = ear tip damage only and 6 ear tip damage plus moderate to heavy damage below tip on all of the ears from a plot.

${ }^{\mathrm{z}}$ Values within a column by hybrid followed by the same letter are not significantly different, least significant difference $P=0.05$. sistance to Maize Insects, CIMMYT, Mexico, 9-11 Nov. 1987

4. Davis, F. M., Henderson, C. A., and G. E. Scott. 1972. Movements and feeding of larvae of the southwestern corn borer on two stages of corn growth. J. Econ. Entomol. 65:519-521.

5. Davis, F. M., and Williams, W. P. 1980. Southwestern corn borer: comparison of techniques for infesting corn for plant resistance studies. $\mathbf{J}$. Econ. Entomol. 73:704-706.

6. Davis, F. M., and Williams, W. P. 1983. Second-generation southwestern corn bore (Lepidoptera: Pyralidae): ear and stalk damage to susceptible and resistant maize. J. Econ Entomol. 76:507-509.

7. Davis, F. M., and Williams, W. P. 1994 Evaluation of reproductive stage maize for resistance to the southwestern corn borer (Lepidoptera: Pyralidae) using visual rating scores of leaf sheath and husk damage. J. Econ. Entomol. 87:1105-1112.

8. Diener, U. L. 1989. Preharvest aflatoxin contamination of peanuts, corn, and cottonseed: a review. Biodeterior. Res. 2:217-244.

9. Gourama, H., and Bullerman, L. B. 1995. Aspergillus flavus and Aspergillus parasiticus: aflatoxigenic fungi of concern in foods and feeds: a review. J. Food Prot. 58:1395-1404.

10. Gray, F. A., Faw, W. F., and Boutwell, J. L. 1982. The 1977 corn-aflatoxin epiphytotic in Alabama. Plant Dis. 66:221-222.

11. Guthrie, W. D., Lillehoj, E. B., McMillian, W. W., Barry, D., Kwolek, W. F., Franz, A. O., Catalano, E. A., Russell, W. A., and Widstrom, N. W. 1981. Effect of hybrids with different levels of susceptibility to second-generation European corn borers on aflatoxin contamination in corn. J. Agric. Food Chem. 29:1170 1172.

12. Harrison, J. C., Carvajal, M., and Garner, R. C. 1993. Does aflatoxin exposure in the United Kingdom constitute a cancer risk? Environ. Health Perspect. 99:99-105.

13. Lillehoj, E. B., Kwolek, W. F., Zuber, M. S., Bockholt, A. J., Calvert, O. H., Findley, W. R., Guthrie, W. D., Horner, E. S., Josephson, L. M., King, S., Manwiller, A., Sauer, D. B. Thompson, D., Turner, M., and Widstrom, N. W. 1980. Aflatoxin in corn before harvest: interaction of hybrids and locations. Crop Sci. 20:731-734.

14. Lillehoj, E. B., Kwolek, W. F., Zuber, M. S., Horner, E. S., Widstrom, N. W., Guthrie, W. D., Turner, M., Sauer, D. B., Findley, W. R., Manwiller, A., and Josephson, L. M. 1980. Variation between hybrids developed for specific regions but grown at diverse locations. Plant Soil 54:469-475.

15. Lillehoj, E. B., McMillian, W. W., Guthrie, W. D., and D. Barry. 1980. Aflatoxin-producing fungi in preharvest corn: inoculum source in insects and soils. J. Environ. Qual. 9:691-694.

16. Lillehoj, E. B., McMillian, W. W., Widstrom, Guthrie, W. D., Jarvis, J. L., Barry, D., and Kwolek, W. F. 1984. Aflatoxin contamination of maize kernels before harvest. Mycopathologia 86:77-81.

17. McMillian, W. W. 1983. Role of arthropods in field contamination. Pages 20-22 in: Aflatoxin and Aspergillus flavus in corn, U. L. Diener, R. L. Asquith, and J. W. Dickens, eds. South Coop. Ser. Bull. 279. Ala. Agric. Exp. Stn., Auburn.

18. McMillian, W. W., Widstrom, N. W., Wilson, D. M., and Hill, R. A. 1980. Transmission by maize weevils of Aspergillus flavus and its survival on selected corn hybrids. J. Econ. Entomol. 73:793-794.

19. McMillian, W. W., Wilson, D. M., and Widstrom, N. W. 1985. Aflatoxin contamination of preharvest corn in Georgia: a six-year study of insect damage and visible Aspergillus flavus. J. Environ. Qual. 14:200-202. 
20. Munkvold, G. P., Hellmich, R. L., and Showers, W. B. 1997. Reduced Fusarium ear rot and symptomless infection in kernels of maize genetically engineered for European corn borer resistance. Phytopathology 87:10711077.

21. Payne, G. A. 1992. Aflatoxin in maize. Crit. Rev. Plant Sci. 10:423-440.

22. Scott, G. E., and Davis, F. M. 1974. Effect of southwestern corn borer feeding on maize. Agron. J. 66:773-774.

23. Scott, G. E., and Zummo, N. 1988. Sources of resistance in maize to kernel infection by Aspergillus flavus in the field. Crop Sci. 28:504507.

24. Scott, G. E., and Zummo, N. 1990. Preharvest kernel infection by Aspergillus flavus for resistant and susceptible maize hybrids. Crop Sci. 30:381-383.

25. Scott, G. E., and Zummo, N. 1990. Registration of Mp313E parental line of maize. Crop Sci. 30:1378.

26. Scott, G. E., and Zummo, N. 1992. Registration of Mp420 germplasm line of maize. Crop Sci. 32:1296.

27. Shane, S. M. 1994. Economic issues associated with aflatoxins. Pages 513-527 in: The Toxicology of Aflatoxins: Human Health, Veterinary, and Agricultural Significance. D. L. Eaton and J. D. Groopman, eds. Academic Press, New York.

28. Throne, J. E., Baker, J. E., and Scott, G. E. 1995. Development of maize weevils (Coleoptera: Curculionidae) on corn lines resistant to an aflatoxin-producing fungus. Environ. Entomol. 24:944-949.

29. Widstrom, N. W., Lillehoj, E. B., Sparks, A. N. and Kwolek, W. F. 1976. Corn earworm damage and aflatoxin $\mathrm{B}_{1}$ on corn ears protected with insecticide. J. Econ. Entomol. 69:677-679.

30. Widstrom, N. W., Wiseman, B. R., McMillian, W. W., Kwolek, W. F., Lillehoj, E. B., Jellum, M. D., and Massey, J. H. 1978. Evaluation of commercial and experimental three-way corn hybrids for aflatoxin $\mathrm{B}_{1}$ production potential. Agron. J. 70:986-988.

31. Williams, W. P., Buckley, P. M., Sagers, J. B. and Hanten, J. A. 1998. Evaluation of transgenic corn for resistance to corn earworm (Lepidoptera: Noctuidae), fall armyworm (Lepidoptera: Noctuidae), and southwestern corn borer (Lepidoptera: Pyralidae) in a labo- ratory bioassay. J. Entomol. Sci. 33:105-112

32. Williams, W. P., and Davis, F. M. 1985. Southwestern corn borer damage to maize: influence of plant age at time of larval infestation. Agric. Ecosyst. \& Environ. 12:201-205.

33. Windham, G. L., and Williams, W. P. 1998 Aspergillus flavus infection and aflatoxin accumulation in resistant and susceptible maize hybrids. Plant Dis. 82:281-284.

34. Zuber, M. S., Calvert, O. H., Lillehoj, E. B., and Kwolek, W. F. 1976. Preharvest development of aflatoxin $\mathrm{B}_{1}$ in corn in the United States. Phytopathology 66:1120-1121.

35. Zuber, M. S., Darrah, L. L., Lillehoj, E. B., Josephson, L. M., Manwiller, A., Scott, G. E. Gudauskas, R. T., Horner, E. S., Widstrom, N W., Thompson, D. L., Bockholt, A. J., and Brewbaker, J. L. 1983. Comparison of openpollinated maize varieties and hybrids for preharvest aflatoxin contamination in the southern United States. Plant Dis. 67:185-187.

36. Zummo, N., and Scott, G. E. 1989. Evaluation of field inoculation techniques for screening maize genotypes against kernel infection by Aspergillus flavus in Mississippi. Plant Dis. 73:313-316. 